\title{
TRABALHO E IMIGRAÇÃO: EXPERIÊNCIAS NAS NARRATIVAS DOS HAITIANOS/ HAITIANAS ACERCA DAS FRONTEIRAS
}

\author{
Joselene Ieda dos Santos Lopes de Carvalho ${ }^{1}$
}

\begin{abstract}
RESUMO: Este artigo é um recorte de minha tese de Doutorado da qual durante os anos de 2016 a 2020 entrevistei haitianos e haitianas que viviam na cidade de Cascavel, localizada na região Oeste do Paraná. Dentre as principais temáticas, elencadas em meu trabalho, as seguintes foram preponderantes: i) trajetórias de vida; ii) trajetórias de imigração; iii) trajetórias de trabalho e iv) trajetórias de luta. Ademais, especificamente para este texto, proponho analisar que para além das fronteiras físicas ultrapassadas pelos haitianos desde que saíram do Haiti para que chegassem até o Brasil, houve também as fronteiras do imaginário popular que mesmo após anos da imigração haitiana para o Brasil, parte da população brasileira insiste em lidar com os imigrantes como "os outros". Deste modo, busco sintetizar alguns dos aspectos vivenciados pelos haitianos durante o processo de emigração do Haiti, as dificuldades do trajeto até a chegada no Acre e as condições vividas no acampamento e por fim, como interpretam intrinsecamente suas experiências de trabalho e imigração no Oeste do Paraná, região da qual no último levantamento realizado em 2019 condizia com aproximadamente dez mil imigrantes haitianos.
\end{abstract}

Palavras-chave: Imigração haitiana; Trabalhadores; Fronteiras;

\section{WORK AND IMMIGRATION: EXPERIENCES IN NARRATIVES BY HAITIANS/ HAITIANS ABOUT BORDERS}

\begin{abstract}
This article is an excerpt from my Doctoral thesis, which during the years 2016 to 2020 I interviewed Haitians and Haitians who lived in the city of Cascavel, located in the western region of Paraná. Among the main themes, listed in my work, the following were preponderant: i) life trajectories; ii) immigration trajectories; iii) trajectories of work and iv) trajectories of struggle. In addition, specifically for this text, I propose to analyze that beyond the physical borders crossed by Haitians since they left Haiti to reach Brazil, there were also the boundaries of the popular imagination that even after years of Haitian immigration to Brazil, part of Brazilian population insists on dealing with immigrants as "the others". In this way, I try to synthesize some of the aspects experienced by Haitians during the process of emigration from Haiti, the difficulties of the journey to their arrival in Acre and the conditions experienced at the camp and finally, how they intrinsically interpret their work and immigration experiences in Western Paraná, a region from which in the last survey carried out in 2019 it matched approximately ten thousand Haitian immigrants.
\end{abstract}

Keywords: Haitians immigration; Workers; Borders.

\footnotetext{
${ }^{1}$ Doutora em História. Universidade Estadual do Oeste do Paraná, campus de Marechal Cândido Rondon. E-mail: joohieda@ hotmail.com
} 


\section{APRESENTAÇÃO}

Em 2016 quando Donald Trump foi eleito presidente dos Estados Unidos, uma de suas pautas que infelizmente não ficou apenas no palanque, era a de fortalecer as políticas de imigração na fronteira entre o México e os Estados Unidos. No entanto, os discursos xenofóbicos não se restringiriam apenas a este país.

No caso brasileiro, desde 2010 até 2018 a principal nacionalidade de imigrantes que chegaram nos postos da Polícia Federal, foram os haitianos (OBMIGRA, 2014; OBMIGRA, 2018) que embora tenha sido fornecido o "visto por questões humanitárias", não deixaram de serem entendidos como "caso de polícia", sendo a "Lei do Estrangeiro" a principal legislação para a regularização destes sujeitos no Brasil (constituída durante o período da ditadura militar pela Lei de Segurança Nacional).

Após intensa luta dos setores de acolhimentos dos imigrantes, foi criada a Lei da Migração em 2017. Porém, o Instituto Brasileiro de Geografia e Estatística (IBGE) em 2019 divulgou que eram praticamente inexistentes as políticas públicas em âmbito municipais para os imigrantes no país.

\section{A FRONTEIRA QUE PERDURA SÉCULOS}

Durante o século XIX, mais especificamente entre 1791 a 1804 o Haiti foi palco de um dos eventos históricos mais importantes do mundo: o grito pela liberdade e independência conquistado pela população negra afro-caribenha na luta contra as amarras da escravidão.

Além disso, o professor Handerson Joseph destaca que:

No início do ano de 1830, judeus de todo o mundo, inclusive da Polônia, Líbano, Síria e Egito, encontraram refúgio no Haiti. Eles ouvem sobre a terra da Liberdade, leem artigos publicados pelos principais jornais da época, segundo os quais basta pisar o solo haitiano para ficar livre para sempre enquanto são perseguidos na Europa ${ }^{2}$.

\footnotetext{
2 Disponível em: $\quad$ https://profileayiti.blogspot.com/2019/11/comment-haiti-sauve-lesjuifs.html?fbclid=IwAR2pnPZCq6yu-vmHWBYegYea0naCAPgy1DnjXyE8UFVCIxLwxODSvjNIRpY. Acesso em: 10 de out. de 2020.
} 
O Haiti representava liberdade, liberdade da qual estava distante para alguns países em ser alcançada, como era o caso do Brasil que vivia o contexto da escravidão. Ademais, Joseph (2019) destaca que se hoje o mundo enxerga o Haiti como um lugar de emigração, durante o século XIX, este país acolhia com generosidade e solidariedade históricas pessoas do mundo inteiro, sem que existisse normas mundiais que exigissem tal acolhimento.

É importante destacar tais aspectos, pois, a visão que se tem do Haiti hoje é a de um país economicamente falido, sem que o Estado consiga fornecer o mínimo de condições dignas para a maioria da população. No entanto, ainda falta em uma perspectiva decolonial, compreender a partir do processo histórico da luta pela independência a fronteira iniciada por Napoleão Bonaparte e demais potências europeias à colônia de exescravizados que tornaram a ilha de São Domingos, a República do Haiti.

O Haiti durante o século XVIII e parte do XIX, destacava-se como uma das principais colônias de produção do açúcar da qual cerca de meio milhão de escravos eram responsáveis pelo trabalho nos engenhos. Essa população sofria as mais variadas formas de tortura e maus-tratos, de modo que qualquer reclamação era o suficiente para que fossem mortos.

Após organizar um exército de ex-escravos, Toussaint derrotou os franceses e os espanhóis que buscavam estabelecer um novo domínio no local. Este líder acreditava que Napoleão Bonaparte faria acordo com a população haitiana, pois, havia estudado os ideais iluministas de "liberdade, igualdade e fraternidade", acreditando que a França aprovaria tais políticas para suas colônias. Toussaint foi preso e exilado e mesmo sem a sua liderança principal, os haitianos continuavam vitoriosos nas batalhas contra os franceses.

O que ocasionou, segundo Gorender (2004), uma fronteira de correlação de forças do Haiti com os demais países em uma escala mundial:

\footnotetext{
Quando exilado, Simon Bolívar encontrou abrigo no Haiti, onde recebeu de Pétion proteção, ajuda financeira, dinheiro, armas e até uma prensa tipográfica. No entanto, Simon Bolívar excluiu o Haiti dos países latino-americanos convidados à Conferência do Panamá, em 1826. O isolamento internacional acentuou o atraso e agravou as dificuldades históricas, após uma das mais heroicas lutas emancipadoras do hemisfério ocidental. (GORENDER, 2004, p.8)
} 
A partir desta breve síntese sobre a fronteira construída em relação ao Haiti, devido sua própria história, é possível de compreendermos que as dificuldades vividas pela população haitiana não são resultantes apenas de desastres naturais. Por isso, recuperar este aspecto histórico permite-nos pensar sobre como as relações de bloqueio econômico que perduraram séculos com o Haiti, fizeram com que de um país de economia próspera, ocupasse os piores índices de desenvolvimento humano (COGGIOLA, 2010).

Para além de um discurso de perdas físicas, Lahens destaca situações que não estiveram inertes para o povo haitiano.

\begin{abstract}
Escrever para repatriar a desgraça ao lugar que lhe cabe. O centro. Porque o que se abateu sobre nós no dia 12 de janeiro não é uma desgraça de periferia, uma desgraça do "quarto mundo". É uma desgraça de primeiro mundo, assim como o de todos os outros. (...) O mundo se debruçou, generoso, e balbuciou as primeiras palavras de uma solidariedade que anunciava nova. Bastou descerrar os olhos e ela já assumia os traços claros da antiga. Os grandes pássaros de rapina, tão ávidos pela morte que serve de repasto, já abriram as asas. A bela toalha branca dos festins já foi estendida por cima da falha. (LAHENS, 2012, p. 12).
\end{abstract}

O que Lahens chama atenção em seu texto está para além da ineficiência do Estado haitiano em se reerguer após o terremoto, a autora salienta a falta de colaboração de outros países que enalteciam discursos de ajuda humanitária, entendendo-os como falácias, visto que a desgraça haitiana é justamente o que possibilita que estruturalmente o Haiti se torne cada vez mais dependente de países imperialistas.

Deste modo, mesmo depois de anos após o terremoto o caos ainda permaneceu no Haiti. A autora discute em sua obra "Falhas" (2012) as dificuldades vivenciadas por aqueles que sobreviveram a tragédia e destaca o que sobrou do terremoto: sonhos destruídos, casas destroçadas, familiares e amigos mortos.

Semelhante aos aspectos que a autora narra, Wladimy me contou sobre a dificuldade em prosseguir com sua vida de professor no Haiti. Por isso, após procurar saídas viáveis, entendeu que a imigração significaria uma nova chance não apenas para ele, mas para toda sua família que havia sobrevivido ao terremoto.

Eu decidi imigrar pela minha família né? Porque pra mim era muito difícil sair de lá, eu trabalhava e ajudava a ter comida em casa. Mas quando falei para os meus pais, eles acharam que isso era o melhor, aí eu me animei. Do resto da história, você já sabe... dificuldade e só dificuldade! (WLADIMY, 2016). 
A narrativa de Wladimy e de outros imigrantes haitianos me permitem afirmar que a decisão de imigrar para o Brasil não é uma escolha simples. Não se trata de dormir e ao acordar organizar as malas e esperar o próximo voo. Se a dificuldade em sobreviver no Haiti é corriqueira, conforme já pontuado neste texto, cabe-nos o questionamento acerca de como pessoas como Wladimy conseguiram imigrar.

Por não se tratar de aspectos homogêneos, existem diversas formas de realizar a imigração, elencarei três das que foram mais comuns nas entrevistas realizadas com estes imigrantes: a primeira trata-se da família no Haiti que se reúne e consegue juntar o dinheiro suficiente para a realização da viagem. Em casos como o de Jean, seu pai vendeu a casa em que morava para que fosse possível que seu filho imigrasse; a segunda maneira foi narrada por Mike, ainda corresponde as redes de sociabilidade familiares, seus irmãos mais velhos que já haviam imigrado para o Canadá e para os Estados Unidos, mandaram dinheiro suficiente para que Mike conseguisse sair do Haiti, mesmo que não fosse para encontra-los nos Estados Unidos e Canadá. E por terceiro, apresento a maneira considerada como mais perigosa, porém, comum aos imigrantes que são as redes ilegais de tráfico.

Sobre a vinda organizada pelas redes ilegais,

Raketè é um sujeito fundamental que age no contexto da dyaspora. É alguém contratado ou que se oferece para intermediar o processo de traslado de uma pessoa ou grupo de um país a outro. Um raketè sempre cobra por seus serviços e sempre recebe. É uma categoria em ação transnacional. Às vezes, raketè é chamado de ajans, pode ser uma agência de turismo ou de viagens, ou pessoa que presta serviços burocráticos, trabalha com venda de passagens, câmbio de moedas, agiotagem, serviços consulares para documentação em processos migratórios, emissão de documentos no país, venda de vistos falsos, etc. (CONTINGUIBA, COTINGUIBA, 2016, p.177).

O contexto detalhado por Wladimy corresponde ao de uma vida no Haiti em que mesmo antes do terremoto não conseguiria juntar dinheiro o suficiente para imigrar. Quando optou por seguir destino ao Brasil, foi porque não conseguia enxergar no Haiti uma condição de vida melhor para si e para seus familiares. 
Assim como, Mamed (2016), Cotinguiba (2014), Bortoloto (2019) escreveram em seus trabalhos, para compreender a imigração haitiana para o Brasil, é necessário pensar além dos que partiram, mas também sobre os familiares que ficaram no Haiti.

Wladimy narrou que quando conversou com sua família sobre sua decisão, procurou um raketè direcionado por um amigo que já havia imigrado. Em menos de um mês, Wladimy estava com sua mochila pronta para vir ao Brasil. Disse-me que mesmo optando pela rede ilegal precisou fornecer uma parcela de dinheiro como "garantia" de pagamento do trajeto.

Este sistema de agiotagem já foi pesquisado por demais autores como Martins (2014) e constatado que os haitianos se endividavam entre U\$3000 à U\$6000 dólares norte-americanos para a viagem até o Brasil, o que chega a ser considerado como o dobro do que gastariam legalmente. No entanto, conforme pontuei acima, a vida que Wladimy levava juntamente com sua família no Haiti, o impossibilitava de imigrar legalmente.

As inúmeras dificuldades que Wladimy relatou foram alvo em 2012 da Comissão Parlamentar de Inquérito (CPI) que solicitou à Agência Brasileira de Inteligência (ABIN) a investigação dos "coiotes" que atuavam desde a saída no Haiti, até a chegada dos haitianos tanto pelo Acre quanto pela Amazônia. Entre as considerações destacadas pela comissão, constavam que além de haitianos haviam brasileiros envolvidos nas redes ilegais.

Wladimy contou que entre as situações que precisou viver na viagem, o sentimento de morte foi o mais presente. "Ainda hoje quando fecho os olhos, eu sinto como se há qualquer momento eu fosse morrer!". Ao viajar à margem de países como Equador e o Peru, Wladimy e demais haitianos que estavam em seu grupo dirigido por um coiote eram pressionados a passarem despercebidos pelos postos de fiscalização.

"Eu fiquei dois dias sem comer nada. Eu tinha medo de gastar o pouco de dinheiro que eu tinha trazido e encontrar um policial no Peru e não ter dinheiro pra dar pra ele", segundo Wladimy, o coiote que estava responsável por sua imigração já havia informado que se encontrassem a polícia, deveriam dar-lhes dinheiro para que fosse possível prosseguir a viagem.

O que dificultava segundo pontuou Wladimy, era que o coiote não estava com o grupo de imigrantes todo o tempo, havia trechos que eram direcionados a percorrer sozinhos e o desespero aumentava ainda mais por saber que não havia como ter a certeza 
de que estavam no caminho certo, aliado ao fato de não saber se poderiam confiar em quem havia lhes dito o caminho.

Semelhante com a narrativa de Wladimy, Benjamin me contou que "quando a gente chegou na cidade de Trujillo no Peru né? O cara do carro disse que como a gente era em nove pessoas, ia cobrar mais caro. Eu tinha dinheiro pra pagar minha parte, mas tinha outros que não tinham mais".

O contexto narrado por Benjamin, tratava-se do trajeto de Trujillo até Lima, aproximadamente $550 \mathrm{~km}$ de distância e cerca de oito horas e vinte minutos de carro. Se Benjamin tivesse que percorrer esse trecho a pé, aumentava para $747 \mathrm{~km}$ dos quais gastaria cerca de cento e sessenta e duas horas! Benjamin me disse que não fazia ideia da dificuldade de ter que percorrer um trecho desta distância, mas que se não tivesse conseguido uma carona com um grupo de ônibus de haitianos, "eu teria que fazer! Não tinha pra onde ir! Podia morrer, mas ia ter que tentar!”

Estes são alguns dos embates vividos pelos haitianos para conseguir chegar até o Brasil, dos quais suas vidas estiveram em constante ameaça. Ao questionar Wladimy e Benjamin sobre o que impossibilitou que conseguissem adquirir o visto humanitário no Haiti, me disseram que dentre as exigências, poucas eram as que se tornavam possíveis no contexto em que viviam no país.

Ao pesquisar sobre as regras, encontrei que:

Para se candidatar à permissão, o postulante deve ter passaporte em dia, ser residente no Haiti (o que deve ser comprovado por atestado de residência) e apresentar atestado de bons antecedentes. Com todos os documentos em mãos, deve ainda pagar U\$200 dólares para a emissão do visto. Segundo dados da Embaixada brasileira em Porto Príncipe, em fevereiro de 2012 foram concedidos apenas $30 \%$ dos 100 vistos mensais permitidos pela resolução. (FERNANDES, FARIA, 2016, p.102).

Wladimy me disse que ao procurar na embaixada quais eram os documentos necessários parou de ler quando uma das primeiras exigências era ter residência comprovada no Haiti, "como vou provar isso? Eu morava com meu pai que perdeu tudo, até a casa com o terremoto!"

Deste modo, a vinda para o Brasil em busca de conseguir retirar o visto humanitário nas fronteiras brasileiras foi constante nas narrativas dos haitianos. No entanto, as fronteiras não deixaram de ser vividas, pelo contrário, ao atravessar as 
dificuldades narradas acima, chegar ao Brasil exigiu lidar com demais adversidades, além das físicas as do imaginário popular dos brasileiros.

\section{A FRONTEIRA BRASILEIRA NO ACRE}

"Que eu me lembre, tem duas vezes em que mais me senti feliz, a primeira foi quando nasceu minha filha e a segunda, foi quando atravessei a fronteira do Peru com o Brasil", recordou Benjamin, enquanto tinha os olhos cheios de lágrimas por ter me narrado a dificuldade não apenas em chegar até o Brasil, mas depois da fronteira, buscar cotidianamente romper os demais problemas.

“A gente sente muito medo das fronteiras né?" continuou narrando quando relembrou que mesmo ao sentir medo, se sentia feliz por ter sobrevivido para encontrar os taxistas brasileiros que os levariam até a cidade de Assis Brasil no Acre.

Segundo Mamed:

No Posto Alfandegário de Assis Brasil, na tríplice fronteira entre Brasil, Peru e Bolívia, os imigrantes se apresentavam ao serviço de controle migratório da Polícia Federal para registrar em seus passaportes a data de ingresso em território brasileiro. Após isso, pela mesma rodovia Interoceânica, seguiam até as cidades gêmeas de Epitaciolândia e Brasileia, onde existe a delegacia de Polícia Federal responsável pela região de fronteira, unidade na qual davam entrada à solicitação de refúgio. Até abril de 2014, estava sediado na cidade de Brasileia o acampamento público de acolhida aos imigrantes. Entretanto, após a mudança dessa estrutura de serviço para a capital do estado, depois de passarem pela Polícia Federal, eles se dirigiam até o novo endereço do abrigo, localizado na cidade de Rio Branco. (MAMED, 2016, p.12).

Assim como Benjamin narrou, Wladimy me disse que se sentia vitorioso em ter conseguido chegar ao Brasil depois de passar por tantas dificuldades. "Era a luz no fim do túnel né? Pelo menos eu pensava que era (risos)". O relato de Wladimy permite evidenciar que mesmo após a travessia, houveram desafios tão difíceis quanto os vividos durante a viagem.

As fronteiras são representativas, pois, mesmo quando deixam de existir fisicamente, persistiram nas relações com os brasileiros. Essas separações se tornaram uma construção do Estado moderno em busca de segregar aquilo que é diferente. Além disso, Stuart Hall (2005) chama atenção para a implicação que as fronteiras têm acerca 
da identidade das pessoas, surgem para construir uma ideia de nação que parece ser natural, mas que é construída historicamente e sustenta-se no pressuposto de "nós, somos diferentes deles".

$\mathrm{Na}$ última década as fronteiras em relação aos haitianos, venezuelanos, senegaleses, bolivianos, têm se tornado cada dia mais presentes e difíceis de serem corrompidas no Brasil. O historiador camaronês Achille Mbembe $^{3}$ destacou que a fronteira é sobretudo como "controlar os corpos, mas também o movimento", e no caso dos grupos citados, recebe um caráter ainda mais controlador, pois, são estigmatizados e, portanto, não se tornam apenas invisíveis, mas contestados.

Segundo Mamed (2016) a fronteira do Acre foi a que registou mais entrada de imigrantes haitianos entre 2010 e 2015. Por isso, devido o grande fluxo de imigração, fez com que o governo acreano tivesse que organizar um acampamento de acolhimento.

Wladimy relembra sua trajetória no acampamento em 2012 e destaca "fiquei alegre por encontrar tantos haitianos, mas depois fiquei desesperado. Pra onde íamos todos nós? Será que tinha passado por tudo isso pra ficar dependendo de ajuda?" Wladimy destacou que havia dificuldade em torno do acampamento acreano, pois, a quantidade de haitianos que ali estavam era muito maior do que o local poderia suportar. Além disso, há relatos de pesquisadores que estiveram no acampamento que destacaram:

\begin{abstract}
A noite vimos que a acomodação no local era impossível, dado o número de pessoas e a capacidade do lugar, e por isso, revezavam-se nos poucos colchões e os demais pelos bancos da praça para dormirem, ou (...) esperavam para descansarem durante o dia (CONTIGUIBA, 2016, p. 180).
\end{abstract}

Wladimy me disse que "quando não havia mais o que fazer, quando eu estava morrendo de vontade de comer e não tinha nada disponível no acampamento, eu resolvi bater palma e pedir pra uma moradora do Acre uma banana, alguma coisa assim, só pra esconder a fome", como Wladimy não sabia o português, pediu que outro colega o acompanhasse, pois, já sabia se comunicar. Para o espanto de Wladimy "era uma senhora de idade, ela apareceu na porta com uma vassoura e xingou a gente, xingou o povo

\footnotetext{
${ }^{3}$ Disponível em: https://revistaserrote.com.br/2019/05/a-ideia-de-um-mundo-sem-fronteiras-por-achillembembe/?fbclid=IwAR2UMA4_1mZ1_g_HBRDIRTehp2tpSbItFNqy_1V576yV4H1gjbJyagapWX4 Acesso em: 10 de out de 2020.
} 
haitiano! Disse que éramos macacos, que íamos roubar o lugar dos brasileiros. Eu nunca quis isso!".

Wladimy me contou que a partir dessa experiência traumática em que foi inclusive chamado de "macaco", percebeu que as fronteiras do imaginário popular seriam difíceis de se corromper. Embora haja apoio de setores como das igrejas católica e evangélicas em recepcionar estes imigrantes, o que se tem percebido é que poucos são os incentivos do governo federal para auxiliá-los, o que os coloca em uma situação deplorável, sem saber onde recorrer.

Depois de seis dias que estava no acampamento, Wladimy me disse que foi avisado de que representantes de um frigorífico do Paraná iriam fazer uma seleção de trabalhadores no outro dia. "Eu fiquei muito feliz! Era uma grande oportunidade de sair do acampamento e de encontrar um trabalho que ia mudar não só a minha vida, mas a da minha família!”.

Wladimy contou que no dia seguinte, antes de amanhecer acordou para tomar banho e aprender com seu colega algumas palavras no português para tentar impressionar o representante do frigorífico. "Pra quê né? Eles chegaram, a gente fez uma fila indiana, olhavam as mãos e as pernas, pra alguns pediram até pra tirar as camisas, perguntavam se a gente era acostumado a trabalho forte e se tinha família que esperava a gente no Haiti”.

Wladimy narrou o processo de triagem ocorrido no século XXI, mas que remete ao Brasil Colônia, período da escravidão no Brasil. Wladimy me disse ter se surpreendido, pois, não imaginava que a seleção seria deste modo. Após terem escolhido mais de sessenta haitianos, pediram que se organizassem para deixar o acampamento o mais rápido possível e seguissem de ônibus até a cidade de Cascavel no Paraná, onde iriam trabalhar.

Wladimy narrou que se por um lado estava feliz por ter sido escolhido, por outro, havia se sentido em uma espécie de "feira", pois, não interessou ao contratante saber sobre suas experiências de vida, apenas sobre o quão poderia aguentar no trabalho, do qual Wladimy já sabia que seria desgastante.

Em relação ao questionamento dos representantes do frigorífico sobre os familiares dos haitianos, tratava-se de um mecanismo capaz de identificar quais seriam os sujeitos que permaneceriam nos piores cargos, como na desossa de frango, onde teriam 
que efetuar movimentos repetitivos e extenuantes por minutos. Saber que há uma família que espera por ajuda financeira, fez com que muitos, como Wladimy, persistissem no trabalho ainda que sob muitas dificuldades.

\section{CONSIDERAÇÕES FINAIS}

Diversos são os elementos possíveis de serem discutidos acerca da imigração haitiana para o Brasil. As fronteiras das quais propus elencar, são alguns dos embates vividos cotidianamente, desde a emigração, o percurso da viagem e posteriormente, na condição de imigrantes no Brasil.

Há fatores que também merecem destaque que perpetuam as fronteiras físicas e imaginárias, como os bairros periféricos em que vivem nas cidades; as péssimas condições de trabalho em que são submetidos e por falta de opções, aceitam; o convívio cotidiano em relação "aos outros", entre demais aspectos.

O Brasil conforme salientou Schwarcz (2019) carrega em sua história a escravidão estruturada em suas raízes. Deste modo, há um pensamento segregacionista em relação aos negros e pobres, no caso dos haitianos vivenciam experiências ainda mais intensas, pois além de serem negros e pobres, são considerados "os outros" por se tratar de imigrantes.

\section{REFERÊNCIAS BIBLIOGRÁFICAS}

BORTOLOTTO, Claudimara. Migração e trabalho na contemporaneidade: os haitianos no Oeste do Paraná. São Paulo, 2019. 351 p. Tese de Doutorado. Faculdade de Ciências e Letras (Campus Araraquara). Universidade Estadual Paulista "Júlio de Mesquita Filho".

COGGIOLA, Osvaldo. Haiti: terremoto, colonização e resistência. O olho da História. Salvador. v.2, n.14, pp.7, junho de 2010.

COTINGUIBA, Marília; COTINGUIBA, Geraldo. Fronteiras e aspectos do rito de mudança de categoria jurídico-política dos sujeitos haitianos em mobilidade transacional no Brasil. BAENINGER, Rosana et. al. Imigração haitiana no Brasil. Jundiaí-SP: Paco Editorial, 2016. 
FERNANDES, Duval. FARIA, Andressa. O visto humanitário como resposta ao pedido de refúgio dos haitianos. Revista brasileira de Estudos Populares. Belo Horizonte, v.34, n.1, p.145-161, jan./abr. 2016.

GORENDER, Jacob. O épico e o trágico na história do Haiti. Estudos Avançados. São Paulo, v. 18, n.50, pp. 295-302.

HALL, Stuart. A identidade cultural na pós-modernidade. Rio de Janeiro: DP\&A, 2005.

LAHENS, Yanick. Falhas. Brasília: Fundação Alexandre de Gusmão, 2012.

MAMED, Letícia. Haitianos na Amazônia: a morfologia da imigração haitiana pelo Acre e o horizonte de inserção precarizada no Brasil. Ruris. Campinas, v. 10. n. 1., pp.73-111, março- 2016.

MARTINS, José Renato et. al. Diáspora haitiana: da utopia à realidade. Foz do Iguaçu- PR: Gráfica Grapel, 2014.

SCHWARCZ, Lilia. Sobre o autoritarismo no Brasil. São Paulo: Companhia das Letras, 2019.

\section{Entrevistas}

1) Benjamin, tinha 34 anos quando o entrevistei e estava trabalhando na construção civil na cidade de Cascavel. No Haiti também trabalhava na construção civil. Foi entrevistado em Julho de 2018.

2) Jean tinha 25 anos quando o entrevistei em Cascavel e trabalhava de repositor no Atacadão Liderança. No Haiti trabalhava na agricultura com sua família, trabalhou na Argentina de garçom. Foi entrevistado em junho de 2016.

3) Wladimy tinha 35 anos quando o entrevistei em Cascavel e trabalhava no frigorífico da Copavel. No Haiti trabalhava de professor de matemática em escolas públicas. Foi entrevistado em julho de 2018. 